\title{
Proposal for psychomotor development in newborns with low weight according to A.R. Luria's conception
}

\author{
Héctor Juan Pelayo González $z^{\mathrm{a}}$ Yulia Solovieva ${ }^{\text {a*}}$, Luis Quintanar Rojas ${ }^{\mathrm{a}}$, \\ Verónica Reyes Meza ${ }^{\mathrm{b}}$, Ricardo Marcelo Jimeno Arce \\ ${ }^{a}$ Faculty of Psychology, Autonomous University of Puebla, Puebla, Mexico \\ ${ }^{\mathrm{b}}$ Tlaxcala Center of Biology of Behavior, Autonomous University of Tlaxcala, Tlaxcala, Mexico \\ ${ }^{c}$ Mexican Institute of Social Insurance, Clinic 8, Tlaxcala, Mexico
}

${ }^{\star}$ Corresponding author. E-mail: yulia.solovieva@correo.buap.mx

Low birth weight has a negative impact on psychomotor development, specifically on motor and perceptual functions. In order to prevent this effect, neurodevelopmental diagnosis should be supplemented by an effective therapeutic system. The aim of this work was to test a program for psychomotor development based on A.R. Luria's concept of three functional brain units or blocks and the necessity of stimulation of the first functional unit in early childhood. Stimulation of subcortical systems associated with psychomotor and cognitive regulation may help to set the basis for positive functioning of the cerebral cortex in the coming years. Vestibular exercises and proprioceptive stimulation were used. All exercises included significant communicative activity as described by Vygotsky and Lisina, which provided positive direct emotional contact between adult and child. Twenty-five babies with low birth weight were included in the study, along with their parents. After 250 days in the program, all the underweight children presented positive functional development. We conclude that positive effects of these programs for correction and psychological development may be achieved during the first year of life. The methods for sensitive diagnosis and correction should be considered by all specialists involved in topics of early development.

Keywords: low birth weight, psychomotor development, subcortical systems, joint activity, early childhood

\section{Introduction}

Low birth weight may have a negative impact on psychomotor development. It is also considered a determinate negative variable of post-natal growth and a strong morbidity factor (Bulletin of the World Health Organization, 1987). Weight between 1,000 and 2,500 grams at birth is classified as low; "extreme low birth weight" is under 1,000 grams (IDC-10, 2010). Hyaline membrane disease, intracranial hem- 
orrhage, and sepsis can develop in newborn children as a consequence of low birth weight. Low or changing muscle tone, absence of straightening and equilibrium reactions, and lack of orientation are frequently detected in these children. Some authors mention that such conditions may lead to or be related to cerebral paralysis (Hack \& Caron, 1983).

Other authors have observed problems with motor coordination in children with low birth weight, such as inability to maintain constant muscle tone, delay in acquisition of posture, and lack of consolidation of motor functions (Romero, 1997).

Various studies have described the high incidence of disturbance in perceptual functions; for example, Skranes (2007) showed a relatively high incidence of visual-motor problems with a history of low birth weight. This author also found low fractional anisotropy in the internal and external capsule and the superior fasciculus using tensor diffusion imaging. Such data makes it possible to suggest that low birth weight has negative effects on the central nervous system and that such negative effects could affect cognitive processes in general.

In our country, after being stabilized in incubators, children with low birth weight are sent home. It is not common for children to receive any kind of therapy or neuro-developmental care as a prevention strategy. As a result, the children spend several weeks without the professional attention that is essential for early psychological development. The families are normally not aware of any probable consequences until the monthly pediatric checkup. Medical attention is certainly essential for the child's future, but intervention in psychological development is also critical for the acquisition of superior or complex organized behavior (Theeboom \& Weiss, 1995).

Creation and application of programs for newborn children is an important interdisciplinary task for neuropsychology, pediatrics, and developmental psychology. We are convinced that the best solution is not to try to deal with problems "when the problem arises", but a preventive approach. This idea is based on the conception of the zone of proximal development proposed by Vygotsky (1991).

In this paper, the authors report on an original program for early psychological development based on joint actions involving psychomotor functions and positive emotional contact between adult and child. Psychomotor functions were considered as complex elementary movements according to the conception of Katona (1988). The main difference between Katona's conception and our program is our inclusion of elementary movements in the joint actions of adult and child, oriented toward positive emotional goals according to activity theory, considering object and subject as essential elements of a child's activity.

\section{Method}

\section{Participants}

Twenty-five newborn children with low birth weight were included in the study. All were assessed by a pediatric and neonatology service. All babies spent an average of 18 days in an intensive care unit to decrease vulnerability to disease. 


\section{Instruments}

Two instruments were applied for assessment of development during the first year:

1. The Vojta development scale to measure "central coordination disorder" by reflex postures and reactions according to seven positions (Vojta, 2011). Figure 1 shows the seven positions on the scale:

$0=$ no disorder in central coordination

$1-2=$ mild disorder in central coordination

3-4 = moderate disorder in central coordination

5-7 = severe disorder in central coordination.

2. The Hellbrügge psychomotor development estimation scale (Hellbrügge et al., 1980), which includes assessment of basic postures of the child by month.

The study was carried out in the Intensive Care Unit at the General Public Hospital of Cholula of the city of Puebla, Mexico.

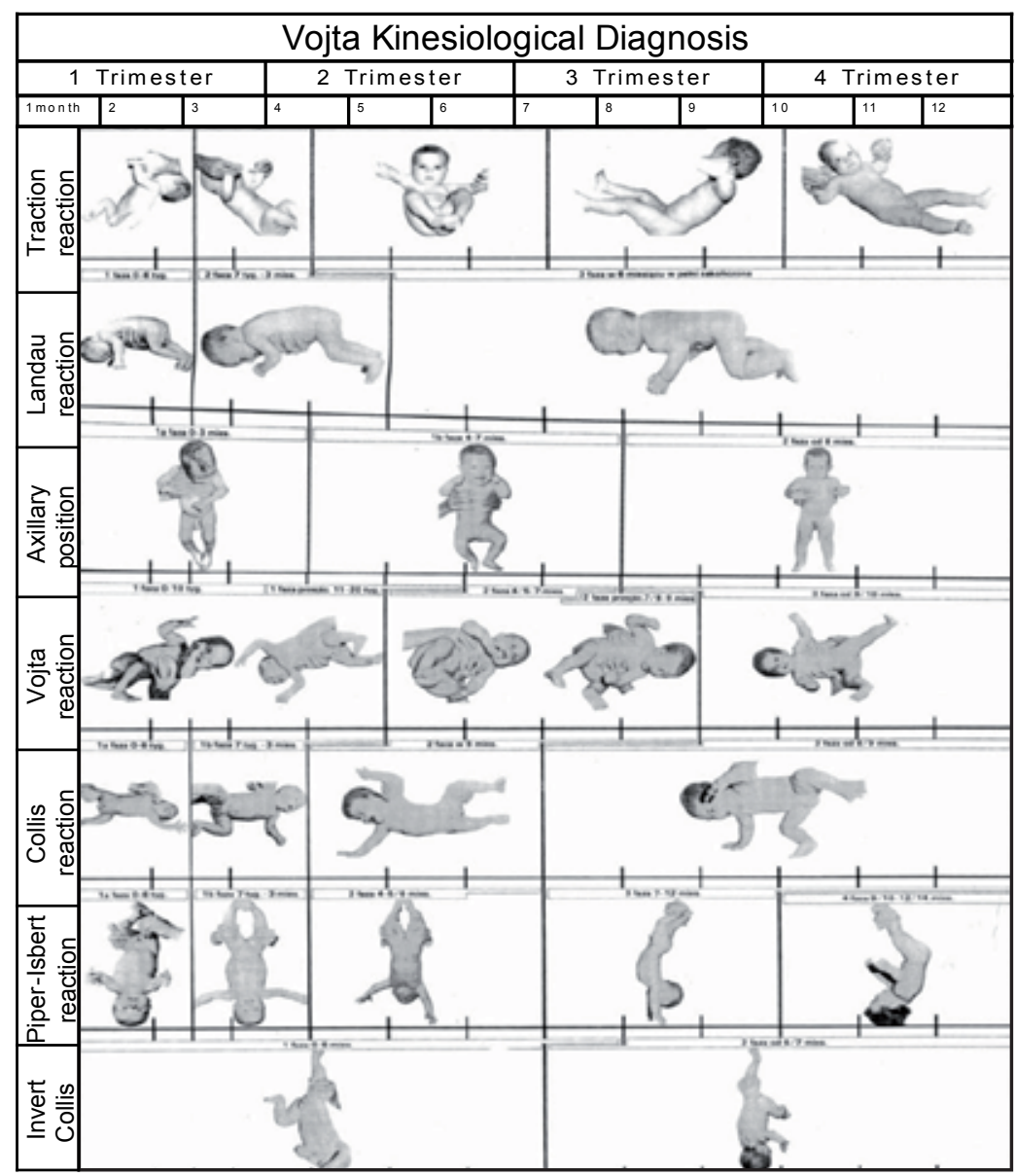

Figure 1. Vojta test of central coordination disorder (CCD) 


\section{Sample}

All children were systematically attended to by the hospital's neonatology service, which determined the babies' weight.

The treatment was explained to the parents in detail. All parents agreed to take part in the study, to allow administration of the program, and to attend all appointments during the treatment. The average educational level of the parents was nine years. All mothers were housewives, while the fathers were workers at large or small enterprises.

The study was carried out under the ethical and social norms and responsibility issued by the General Hospital of Cholula. The participants were selected according to expert judgment criteria applied by pediatricians and at the temporal convenience of the researchers.

\section{Procedure}

1. Children were evaluated in the intensive care unit by neonatology services.

2. Neuro-development evaluation was applied to each child with the help of the Vojta Scale in order to estimate the central coordination disorder.

3. All parents were trained and the content of the program was explained to them. A specialist showed them each exercise, individual competence was achieved, and they were told how to do it three times daily before feeding.

The program was created and approved by the neuropsychology and neurodevelopmental service of the General Hospital in Cholula Puebla. This service is provided and supported by the Master Program on Neuropsychological Diagnosis and Rehabilitation of the Faculty of Psychology of Puebla Autonomous University. During the program, all children were checked every week in order to ensure their progress through the program and to help the parents understand and better perform all the exercises. An expert supervised the performance of the exercises through individual weekly sessions. The program started on the $19^{\text {th }}$ day after the children's birth and initial assessment took place on that day.

The subsequent assessments by the Vojta Scale were on the $150^{\text {th }}$ and $241^{\text {th }}$ postnatal days, to estimate progress in acquisition of elementary motor movements. Additionally, the Hellbrügge Scale was applied to establish functional psychomotor age (Hellbrügge et al, 1980).

\section{Content of the program}

The following exercises were included during the first 5 months. All exercises were joint actions between adult and child, trying to attract the child's attention to an object or person. The parents were told to speak with a highly positive emotional tone and expressive attitude towards the child. The adults were instructed to smile, talk clearly, loudly, and precisely to their children. They could sing songs or rhythmic melodies or just speak kindly to the children during the exercises.

The stages of the study are shown in Figure 2. 


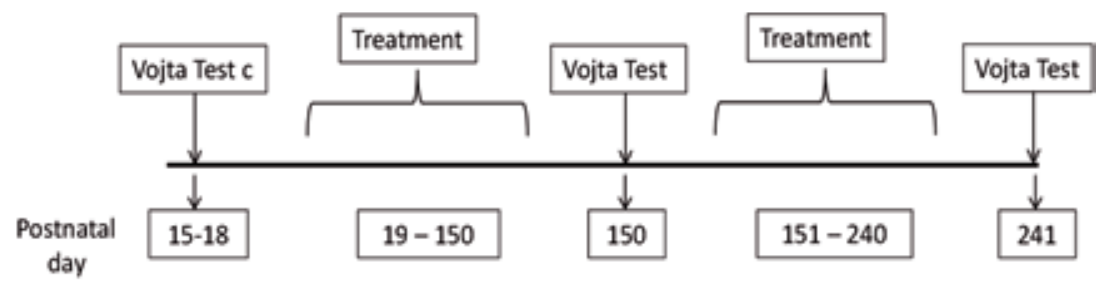

Figure 2. Postnatal age and interventions

The stages of the program are presented below.

\section{Stimulation of tumbling reaction}

1. The adult places the baby in a supine (face-up) position, then holds him or her above the elbow with one hand and holds the hip with the other hand. The child gently turns in the opposite direction from which it is being held. The adult shows toys in the direction that the child's head is pointing, points out and names the toy. 20 seconds on each side.

2. The adult raises the baby, holding him slightly above the waist with both hands, then turns the child slowly sideways, up to 45 degrees. The adult orients the child to watch the toys placed nearby. 20 seconds.

3. The adult places the baby in a supine position, then holds him between the shoulder and elbow with one hand, and between the hip and knee of the same side, with the other hand. The adult gently raises the child to cause the elbow of the other side to support him. The adult sings a song while doing the exercise. 15 seconds on each side.

\section{Stimulation of the straightening reaction}

1. The adult places a small, attractive toy 15 inches from baby's eyes and in the midline of the face. The toy is moved slowly from side to side. The adult names the toy and says that it is moving ("The bird is flying"). 30 seconds.

2. The adult touches the child's cheeks with thumb and fingers simultaneously on both sides and in a circular motion. It is advisable to look into the child's eyes and name parts of his/her face. 30 seconds.

3. The adult holds the baby by the buttocks while his/her hand rests on the stomach. 45 seconds. The adult may walk with the baby around the room, showing different objects (toys, furniture). It is important for the child to achieve the ability to turn his/her head in the direction shown by the adult.

\section{Facilitation of back-neck-shaft straightening}

1. The adult lays the baby face-up and puts an extended hand under the baby's back, while the other hand is placed on the baby's thighs. The adult gently lifts the child, starting from his back. 10-15 seconds. The adult says nice words to the child when he/she rises. 
2. The adult raises the baby, supporting him/her under the armpits, in order for the child to hold his body up for approximately 15 seconds. It is recommended that the child look into the mirror, while the adult says that he/she is big and handsome/beautiful.

3. The adult holds the child from the front of the thighs with one hand. The other hand is placed on the child's abdomen, to lift him/her slowly. 15 seconds. The adult encourages the child: "You can do it, go ahead, look at me, we'll do it together!"

\section{Facilitation of movements for crawling}

1. In a prone (face-down) position, the baby's head is lifted by the chin. 15 seconds. The adult may say to the child: "Look at the mirror! Who's there? Who is so joyful? Look at this teddy bear!"

2. The adult lays the child face-down, then holds one of the baby's heels and raises the leg. With the other hand, the adult presses the child's other leg up slightly, supporting the first leg. 15 seconds. The adult may play music and sing songs during the exercise.

3. The adult extends the baby's arm gently in a prone position, while the opposite leg is also extended. This exercise is done on both sides of the body for about 15 seconds each. The adult looks into the child's eyes and may say, "You are so strong and you can do it so well! You are my hero!"

The second part of the program was applied between the 5th and 8th months of intervention, when the children's age was an average of five months and three weeks. The following more complex exercises were carried out:

\section{Introduction of tumbling reaction as automatic regression to vertical position}

1. The adult holds the baby above the elbow in a supine position and rotates the child slowly from one side to another. 15 seconds. The adult may say to the child, "Look at these nice toys! You will like all of them so much!"

2. The adult lays the baby on his/her back. With one hand, the adult holds the child by the ankle in order to move his/her leg in the direction of the opposite knee. With the other hand, the adult moves the child's hip slightly in the same direction that the leg is moving. The adult may put on some music and sing. 15 seconds.

3. The adult lays the child face-down and tries to strengthen his/her arms and legs as much as possible. The adult may say, "I shall make you laugh with this tickling, you will like it so much!" 15 seconds on each side.

\section{Stimulation of straightening}

1. The adult makes sounds with an interesting object (toy), while the baby is lying on his/her back. The adult encourages the child in head rotation. 20 seconds. The adult names an object (toy) and the sound that the object produces ("The bird is singing" or "The dog is barking"). 
2. The adult gently massages the baby's neck, arms, hips, and legs on both sides at the same time. The baby is in a supine position. 30 seconds. The adult may say, "You have such nice little arms, I will touch you gently, you will like it so much".

3. The adult lays the child on his back and puts one hand between the nape of the neck and the back, trying to raise the baby slightly. The adult may say, "Listen to how this little bee makes the sound zzzzz when you are up and when you are down you will hear no sound! It is a game!"

\section{Facilitation of back-neck-shaft straightening}

1. One adult carries the baby by the buttocks, while another grasps him/her with both hands and draws him/her away from the first adult's abdomen. 15 seconds. One adult may say, "You are so big and strong now! You can do everything by yourself! We shall ask your mother/father to look at you!"

2. The adult places the child in a sitting position on a surface and supports him/her by the back, trying to balance the baby's weight for each side of the body. 15 seconds. The adult may say, "You are sitting so nicely by yourself! You are so big now! And I shall show something new to you now!"

3. The adult holds the child at the top of the hip. 15 seconds. The adult should express positive emotions as the child moves in a vertical position, proposing that he or she look in the mirror.

\section{Facilitation of crawling}

1. The adult supports the baby's chest under the shoulders in a horizontal position to encourage the baby to move his/her arms and legs. 15 seconds. The adult may say, "My baby can move so quickly and can have all toys he/ she wants! Let's go very far now and get these toys!"

2. The adult raises one of the baby's ankles as he lies in a prone position. With the other hand, the adult moves the baby's opposite arm forward. The adult puts on nice music. 30 seconds.

3. The adult performs a circular massage with the tips of the thumbs to the child's scapula (15 seconds), upper back ( 15 seconds), and intercostal zone (15 seconds.). The adult may say nice, expressive words and explain all movements. Songs and melodies might be suggested.

\section{Results}

The majority of parents became positively involved in the program starting from the second month of exercising. We conjectured that from that point they could observe gradual improvement of the children's movements and positive emotional response. The parents were interested in the program and started talking more to the children, which met with a positive response from the children.

It is important to note that the parents learned not only how to do the therapeutic exercises, but also changed the whole manner of their relationship with their children. Positive emotional contact was accompanied by gradual inclusion of 
more complex postures and motor abilities. At each subsequent session, the parents were happy to comment on their children's motor achievements, strength in the arms and legs. They could appreciate stable eye orientation and improved general attention.

Positive changes in psychomotor development were observed from the first to the second assessment and from the second to the third (final) assessment after the completion of the program.

The first Vojta Scale evaluation of complex elementary movements showed an oscillation of values between 1.8 and 4.0, which indicates that the deficit of movement ranged from mild to moderate.

The second assessment was on day 150, after 5 months. Here it was possible to observe changes in the indicators from 1.3 to 3.1 .

The third assessment (after completion of the program) was on day 241, after 8 months. The indicators varied from the highest (1.6) to the (0.5). The results of the three assessments are shown in Figure 3.

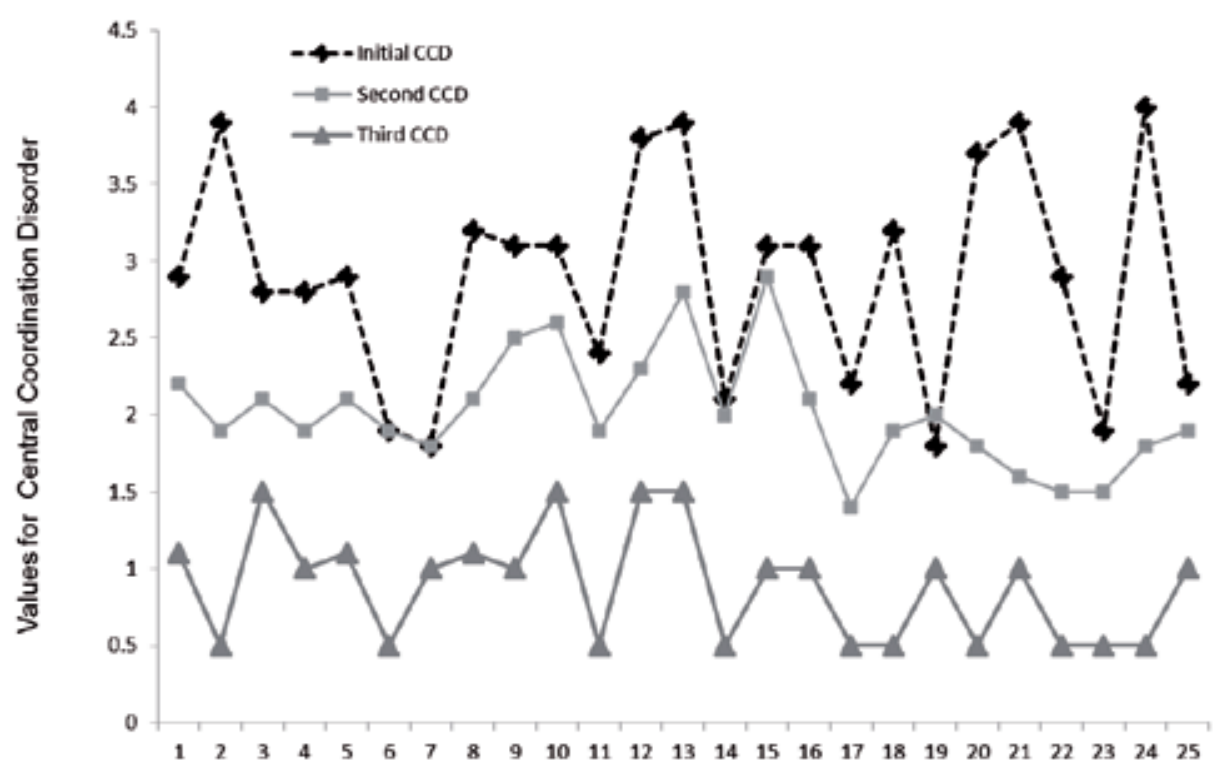

Figure 3. Values for central coordination disorder at three different moments. Each point represents an individual case

Our results show that during the 8 months of working according to the program, the children showed progress in psychomotor development, such as the turning reflex, straightening, pulling, and crawling (Hellbrügge et al., 1980).

\section{Discussion and conclusion}

One of the clinical goals of this study was to improve complex elementary movements and to convert them into object-oriented actions. This decreases the risk of developing some sort of incapacity in the future (Katona et al., 1986). 
The results show that systematic exposure to therapeutic postures stimulates normal motor organization in specific functional systems. We conjecture that such important changes in motor development could be due to the guided intervention effect of the program.

The exercises of the program constantly included external objects, verbal motivating expressions by an adult, and coordinated movements stimulated by an adult. All exercises were carried out in an expressive and positive atmosphere, creating the possibility for constant involvement of the baby in the joint activity with an adult. This strategy is based on the psychological analysis of early infancy (Lisina, 2009; Leontiev, 2009; Elkonin, 1989), and it helped to create a positive zone of proximal development and to achieve a gradually better response from the babies. An additional psychological effect of the program was the disappearance of negative impulsive reactions such as irritability, weeping, excessively frequent breathing, and chaotic movements of the legs and arms with no apparent goal. All the babies were able to orient the movements of their eyes to external goals or according to the emotional attraction of an adult.

For example, the mother's image and voice improved the child's performance during therapy exercises, produced guided sensory orientation effects, and fostered a constant motor orientation. Thus parents should be trained both how to do the exercises and also on how to interact effectively (Pelayo et al., 2013).

We can say that the right development of the motor system makes visual fixation and tracking possible, along with the animation complex (Lisina, 2009; Kamenskaya, 2010). The results of varied treatments for low-birth-weight children point to the importance of the parent swiftly enrolling them in psychomotor developmental stimulation programs (Dawes, 2000).

This psychological disposition of such little children (babies) for immediate environment interaction can be considered as a basis for further formation of more complex functional systems, which combine the proprioceptive, vestibular, and cerebral stem systems (Tisson, 2001). At the same time, it is not possible to assume separate maturation of the psychomotor system without inclusion of high levels of cortical regulation (Machinskaya \& Farber, 2014). On the one hand, it is possible that we are speaking about the functions included in the primary functional unit (Luria, 1970); on the other, according to Luria's conception, no action can be performed with the participation of only one functional unit. This logic makes us believe that the program applied in the study permits better consolidation of coordinated efforts between the first and third functional units (Machinskaya \& Semenova, 2007). Such coordination can be achieved according to the external objective of the actions proposed by the adult to the child within joint positive emotionally communicative activity (Lisina, 2009).

Our results provide only preliminary evidence, which allows us, however, to reach some conclusions about the neuropsychological theory of development in very young children from a historical and cultural perspective. The results suggest that it is possible to start stimulating development at the very beginning through joint activity between adult and child, which later will be of great importance to create behavioral regulation systems (Solovieva et al., 2009). We can claim that early organization of joint activity between adult and child, always initiated by an adult, permits positive results in communicative activity by itself, as was already demon- 
strated by the authors of historic and cultural psychology (Luria, 1977; Elkonin, 1989; Lisina, 2009). Our results point out a clear relation between the development of the nervous system and the level of psychological activity. Positive emotional communication and interaction may require the whole motor sphere, the system of equilibrium, tonic activation, and emotional regulation of activity. The necessity for research into diverse levels of childhood activity has been expressed clearly by the theory of cultural activity (Taliizna, Solovieva \& Quintanar, 2010; Leontiev, 2009).

The program for stimulation of early psychological development, fulfilled as oriented joint activity and not as isolated movements, may be understood as an essential part of the communicative activity necessary for children with neurological risks because of unfavorable birth conditions. Thus, emotional communication with the parent is essential to the emergence of developmental milestones and with them the effects on modulation systems between the first and third functional unit.

Finally, we may say that higher regulatory centers may be involved in cultural actions on this basis, and simultaneously with their direct interactions with subcortical systems of the brainstem and midbrain (Luria, 1973; Machinskaya \& Farber, 2014).

\section{References}

Bulletin of the World Health Organization, (1987). Vol. 85(4). (pp. 249-250).

Dawes, G. (2000). Fetal and neonatal physiology. Chicago: Medical Publishers.

Elkonin, D.B. (1989). Izbranniye psikhologicheskiye trudy [Selected psychological works]. Moscow: Pedagogy.

ICD-10 (2010). International statistical classification of diseases and related health problems. Geneva: World Health Association.

Hack, M., \& Caron, B. (1983). The very low birth weight infant: The broader spectrum of morbidity during infancy and early childhood. Journal of Developmental \& Behavioral Pediatrics, 4(4), 233-287. doi: 10.1097/00004703-198312000-00004

Hellbrügge, T., Lajosi, F., Menara, D., Rautenstrauch, T., \& Schamberger, R. (1980). Diagnóstico funcional del desarrollo durante el primer año de vida [Functional diagnosis of development during the first year of life]. Alcoy (Alicante): Marfil.

Kamenskaya, V.G. (2010). Detskaja psihologija s jelementami psihofiziologii [Child psychology with elements of psychophysiology]. Moscow: Vysshee Obrazovaniye.

Katona, F. (1981). Complex investigation of impaired brain function during the first postnatal months. Acta Pediatrica Academia of Science Hungary, 22(3), 147-164.

Katona, F. (1988). Developmental clinical neurology and neurohabilitation in the secondary prevention of pre-and perinatal injuries of the brain. Early identification of infants with developmental disabilities. New York: Grune \& Stratton.

Kramer, M.S. (1987). Determinants of low birth weight, methodological assessment and metaanalysis. World Health Organ Bulletin, 65(5), 663-737.

Leontiev, A.N. (2009). Psihologicheskie osnovy razvitija rebenka i obuchenija [Psychological bases of development and teaching of a child]. Moscow: Smysl.

Lisina, M.I. (2009). Formirovaniye lichnosti rebenka $v$ obschenii [Formation of personality of a child in communication]. Moscow: Piter.

Luria, A.R. (1970). The functional organization of the brain. Scientific American, 222(3), 66-78. doi: 10.1038/scientificamerican0370-66 
Luria, A. R. (1973). Vvedeniye v neiropsikhologiyu [Introduction to neuropsychology]. Moscow: Moscow University Press.

Luria, A.R. (1977). A child's speech responses and the social environment. In M. Cole (Ed.). Soviet developmental psychology: An anthology (pp. 32-64). New York: White Plains, M.E. Sharpe.

Machinskaya, R., \& Semonova, O. (2007). The role of brain regulatory systems in cortex functional organization and information processing development in primary school children. Psychophysiology, 44, Supp. 1, 100.

Machinskaya, R.I., \& Farber, D.A. (2014). Mozgovye mehanizmy formirovanija poznavatelnoj dejatelnosti $v$ predshkolnom i mladshem shkolnom vozraste [Brain mechanisms of formation of cognitive activity in preschool and primary school age]. Moscow: MPSU; Voronezh: MODEK.

Pelayo, H., Reyes, V., Quintanar, L., \& Solovieva Y. (2010). Changes in motor patterns after a neurodevelopmental intervention in children with neurological risk factor. Developmental Psychobiology, 52, 712.

Pelayo, H., Solovieva, Y., Marroquín, O., Corona, T., \& Quintanar, L. (2013). Propuesta de prevención interactiva para bebés con factores de riesgo neurológico [Interactive prevention proposal for babies with neurological risk factors]. Revista de Ciencias Clinicas [Journal of Clinical Science], 13(1), 21-29.

Romero, P. (1997). Secuelas neurológicas de origen perinatal en su relación con los factores de riesgo: un modelo de estudio [Neurological sequelae of perinatal origin in relation to risk factors: a study model]. Perinatología Reproducción Humana [Perinatology Human Reproduction], 11(3), 161-174.

Skranes, J. (2007). Clinical findings and white matter abnormalities seen on diffusion tensor imaging in adolescents with very low birth weight. Brain, 130(3), 654-666. doi: 10.1093/ brain/awm001

Solovieva, Y., Machinskaya, R., Quintanar, L., Bonilla, M.R., \& Pelayo, H. (2009). Neuropsicología y electrofisiología del TDA en la edad preescolar. México: Colección neuropsicología y rehabilitación BUAP.

Talizina, N., Solovieva, Y., \& Quintanar, L. (2010). La aproximación de la actividad en psicología y su relación con el enfoque histórico-cultural de L. S. Vygotsky [The approach of the activity in psychology and its relation with the historical-cultural approach of L. S. Vygotsky]. Argentina: Novedades Educativas.

Theeboom, M., \& Weiss F. (1995). Motivational, climate, psychological responses, and motor skill development in children's sport: A field-based intervention study. Journal of Sport and Exercise Psychology, 17, 294-311. doi: 10.1123/jsep.17.3.294

Tisson, A. (2001). Neurología perinatal [Perinatal neuropsychology]. Barcelona: Masson.

Van den Boom, D. (1989). Neonatal irritability and the development of attachment. In Kohnstamm, Geldolph A., Bates, John E., Rothbart, Mary Klevjord (Eds.) Temperament in childhood. (pp. 299-318). Oxford: John Wiley \& Sons.

Vygotsky, L.S. (1991). Problema obuchenija i umstvennogo razvitija v shkolnom vozraste [The problem of teaching and mental development at school age]. In L.S. Vygotsky, Pedagogicheskaya psikhologiya [Pedagogical Psychology]. Moscow: Pedagogika. (Original work published 1935)

Vojta, V. (2011). El descubrimiento de la motricidad ideal [The discovery of ideal motor skills]. Madrid: Morata. 